\title{
Recent advances in the treatment of multiple sclerosis
}

This article was published in the following Dove Press journal:

Journal of Experimental Pharmacology

2 November 2010

Number of times this article has been viewed

\author{
Jeffrey L Bennett \\ Augusto A Miravalle \\ University of Colorado, Aurora, \\ CO, USA
}

Correspondence: Augusto A Miravalle University of Colorado, 12631

East 17th Avenue, BI85, Aurora,

CO 80045 , USA

Tel +I 3037242187

Fax +l 3037242202

Email augusto.miravalle@ucdenver.edu
Abstract: Multiple sclerosis (MS) is a chronic inflammatory, immune-mediated, demyelinating, neurodegenerative disorder of the central nervous system. Despite the lack of an etiologic factor, it has been consistently demonstrated that the immune system plays a crucial role in the pathogenesis of MS. The traditional description of immunopathogenesis of MS suggests a preferential CD4+ TH1 cell activity causing tissue damage by the release of pro-inflammatory cytokines and subsequent demyelination and axonal loss. Recent evidence, however, suggests that other immune cells including TH17 cells, CD8+ effector T cells, CD4+ CD25+ regulatory $\mathrm{T}$ cells, and B cells may play a prominent role in MS immunopathology. A better understanding of the molecular and cellular components of the immunopathogenesis of MS is allowing the development of novel therapies.

Keywords: multiple sclerosis, immunopathology, oral medication, clinical trial

\section{Introduction}

Multiple sclerosis (MS) is a leading cause of disability among young adults in North America and Europe. Approximately 2.5 million people worldwide and 400,000 Americans have MS. ${ }^{1}$ Owing to the strong evidence suggesting immune-mediated mechanisms involved in the pathogenesis of the disease, MS therapies have been developed to modulate or suppress inflammatory responses. Current US Food and Drug Administration (FDA) approved treatments for MS include immunomodulators (interferon [IFN]- $\beta$, glatiramer acetate), or immunosuppressants (mitoxantrone, Tysabri ${ }^{\circledR}$ ). These therapies are partially effective, with a wide range of tolerability and safety profiles. Considering the heterogeneity observed with respect to the clinical, radiographic, morphological, and genetic features of the disease, it is possible that various immunological mechanisms are involved in the pathogenesis of the disease. Besides the description of complex orchestrated immune-mediated mechanisms involved in the pathogenesis of the disease, recent pathological and magnetic resonance imaging (MRI) studies support the presence of diffuse tissue injury and neuronal degeneration extending beyond the classical white mater lesions. ${ }^{2,3}$ Therefore, it is imperative in the future to promote the development of individualized therapeutic strategies targeting both inflammatory and degenerative processes. Recent advances in the understanding of molecular and cellular components involved in the inflammatory and immune responses in MS have generated a new armamentarium of immune-based therapies, including several oral therapies in late-phase clinical trials and/or under review by the FDA for relapsing-remitting MS (RRMS). Here we review the most promising emerging therapies in development for the treatment of MS. 


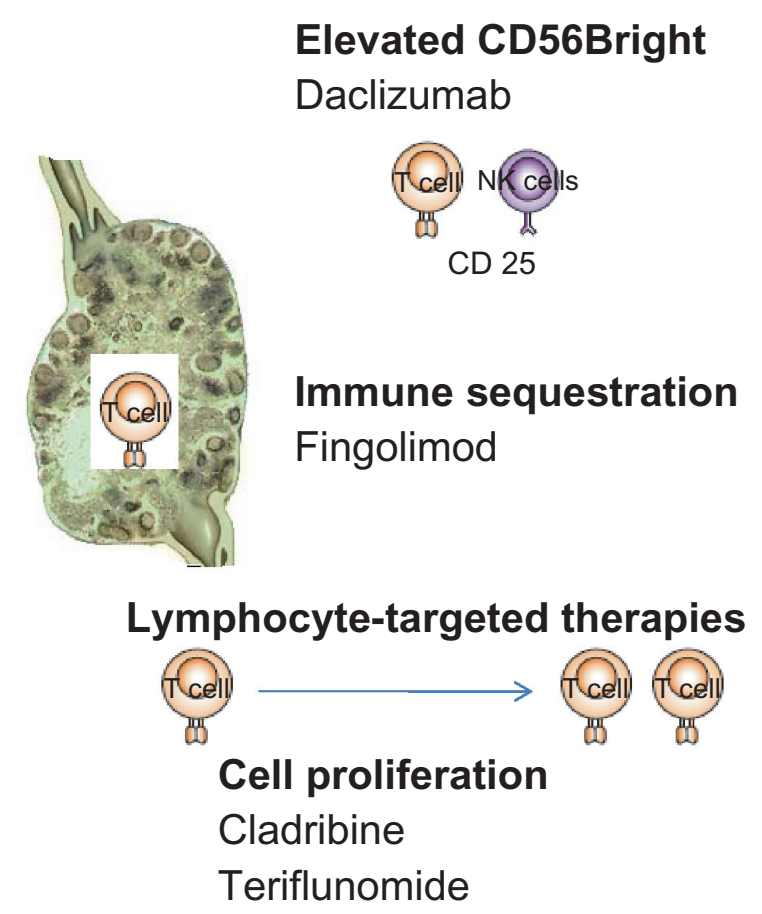

Antibody-dependent cell lysis

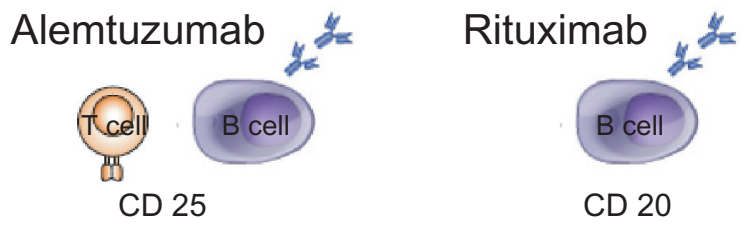

Figure I Proposed mechanism of action of selected emerging therapies in MS.

\section{Oral medications}

\section{Oral cladribine}

Cladribine is a purine nucleoside analog engineered to exploit the specific enzymatic degradation of deoxynucleotides by adenosine deaminase (ADA) present in lymphocytes. Cladribine is phosphorylated intracellularly by deoxycytidine kinase to its active form, 2-chloro-2'-deoxyadenosine triphosphate. Because cladribine is resistant to ADA, it gets incorporated into DNA of lymphocytes and monocytes, and subsequently interrupts DNA replication, causing DNA damage and cell death. ${ }^{1}$ In addition, cladribine possesses epigenetic properties, by inhibiting S-adenosyl homocysteine hydrolase and DNA methylation. ${ }^{4}$ Initially, cladribine was thought to cause a selective and long-lasting reduction of activated CD4+ $\mathrm{T}$ lymphocytes with relatively mild and transient effects on monocytes and neutrophils. Recent data from a subset of patients participating in a Phase III randomized, placebocontrolled trial ${ }^{5}$ has demonstrated that cladribine produces a significant change in multiple peripheral blood subsets includ-

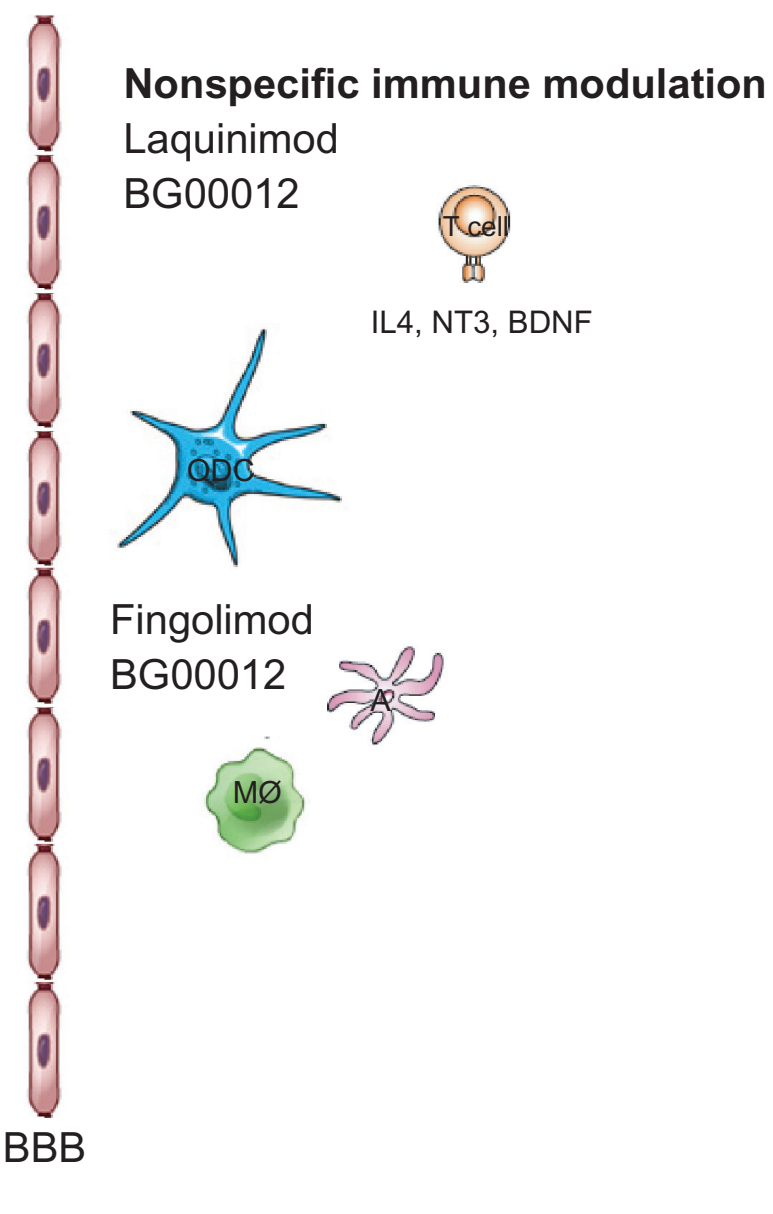

ing an equal reduction in CD4+ and CD8+ T lymphocytes, a moderate reduction in CD56+ natural killer (NK) cells, and a rapid and severe reduction in $\mathrm{B}$ lymphocytes. These findings suggest that cladribine may act at multiple levels to modulate the immune system in relapsing disease: elimination of selfreactive helper and cytotoxic $\mathrm{T}$ cell clones, augmentation of NK regulation of autologous $\mathrm{T}$ lymphocytes, and reduction of effector B cells.

Previous studies evaluating parenteral cladribine in 257 MS patients showed a significant reduction in the number and volume of $\mathrm{T}_{1}$ gadolinium-enhancing lesions, accumulation of $\mathrm{T}_{2}$ lesion volume, relapse rate, and disability progression..$^{3-5} \mathrm{~A}$ recent placebo-controlled Phase III trial using oral cladribine $(3.5$ or $5.25 \mathrm{mg} / \mathrm{kg}$ in the first year, and $3.5 \mathrm{mg} / \mathrm{kg}$ in the second year) in patients with RRMS showed a significant reduction in annualized relapse rates at 2 years compared with placebo (55\%-58\%), and reduction in the risk of progression to disability (hazard ratio for the $3.5-\mathrm{mg}$ group, 0.67 ; $95 \%$ confidence interval [CI]: 
$0.48-0.93 ; P=0.02$, and hazard ratio for the $5.25-\mathrm{mg}$ group, $0.69 ; 95 \%$ CI: $0.49-0.96 ; P=0.03)$. There was an average of $86.8 \%$ in $\mathrm{T}_{1}$ gadolinium-enhancing lesions and a $75.2 \%$ reduction in $\mathrm{T}_{2}$ active lesions. In addition, $80 \%$ of the patients remained relapse free, and $28 \%$ showed no evidence of relapse, MRI activity, or disability progression. ${ }^{6,7}$

Adverse events included headaches, nasopharyngitis, upper respiratory tract infections, and nausea. Lymphopenia occurred more frequently in the active drug group (22\%). Of the patients treated with cladribine tablets, $2.3 \%$ reported herpes zoster infections, although these were localized to the skin and were responsive to preventative treatment. A Phase III trial investigating oral cladribine in clinically isolated syndrome and a Phase IIb trial of combination therapy with IFN- $\beta$-1a is currently underway.

\section{Sphingosine I-phosphate}

Sphingosine 1-phosphate (S1P) is a lysophospholipid present in blood that interacts with members of a group of related G-protein-coupled receptors. Five different S1P receptors have been described (S1P1-S1P5). S1P1, S1P2, and S1P3 receptors are predominantly expressed in cardiovascular and central nervous systems (CNSs). S1P1 is the dominant receptor subtype present on lymphocytes and is required for $\mathrm{T}$ and $\mathrm{B}$ cells to egress from peripheral lymphoid organs and thymus. Fingolimod (FTY720), an oral S1P analog, acts as a partial agonist on $\mathrm{S} 1 \mathrm{P}$ receptors, inducing internalization of the $\mathrm{S} 1 \mathrm{P}$ receptor and subsequent sequestration of central and naïve memory T cells in lymph nodes. Fingolimod is associated with significant decreases in circulating $\mathrm{T}$ and $\mathrm{B}$ cells, with lesser reductions on effector memory T cells. ${ }^{8}$ Due to its lipophilic nature, FTY720 crosses the blood-brain barrier (BBB) and possibly also down-modulates S1P1 in neural cells and astrocytes to reduce astrogliosis, a phenomenon associated with neurodegeneration in MS. ${ }^{9}$ Fingolimod does not appear to affect the functionality of T cells, nor the motility of CNS-resident T cells. This is an important concept suggesting that central immunesurveilance remains intact under fingolimod therapy. ${ }^{10,11}$ In a recent animal study, fingolimod showed promising results in remyelination, mostly mediated by $\mathrm{S} 1 \mathrm{P} 3 / \mathrm{S} 1 \mathrm{P} 5$ receptors. ${ }^{12}$

A multicenter, randomized, double-blind, placebocontrolled phase II and extension study in RRMS patients demonstrated that oral fingolimod at doses of $1.25 \mathrm{mg}$ and $5 \mathrm{mg}$ reduced the number of new focal inflammatory lesions by $80 \%$ and relapse rates by $50 \%$ when compared with placebo. However, due to the presence of dose-related adverse reactions, new trials evaluating lower doses were initiated. Placebo-controlled and active comparator Phase III trials were recently completed. ${ }^{13,14}$ In the placebo-controlled Phase III trial, subjects using $0.5 \mathrm{mg}$ of oral fingolimod demonstrated a significant reduction of annualized relapse rate, risk of accumulation of clinical disability, and MRIrelated outcomes. In the active comparator study, oral fingolimod ( 0.5 and $1.25 \mathrm{mg}$ daily) demonstrated superior efficacy versus intramuscular (IM) IFN (30 $\mu \mathrm{g}$ IM weekly) on relapse rate and MRI outcomes. Adverse reactions in both trials included bradycardia, macular edema, nasopharyngitis, dyspnea, headaches, diarrhea, and nausea. Three cases of basal cell carcinoma, three cases of squamous cell carcinoma, and one case of melanoma were reported. Two fatalities associated with varicella zoster and herpes virus infection and a single case of hemorrhagic encephalitis were also reported with an unclear causal relationship.

\section{Laquinomod}

Laquinimod (quinoline-3-carboxamid) is a once-daily, orally administered immunomodulatory compound that is being developed as a disease-modifying treatment for RRMS. In the experimental autoimmune encephalomyelitis animal model, laquinimod caused a dose-dependent reduction in disease severity, with decreased CD4+ T cell and macrophages infiltrates in spinal cord without resulting in significant systemic immunosupression. ${ }^{15}$ Anti-inflammatory properties of laquinimod are thought to be secondary to a shift to a Th2/Th3 cytokine pattern. In addition it has been suggested that laquinimod may cause a downregulation of major histocompatiability complex class II gene transcription factors, stimulate neurotrophin (NT)-3, NT-4, and brain derived neurotrophic factor (BDNF) secretion, activate interleukin (IL)-4 signaling in CD4+ cells, promote apoptosis of $\mathrm{CD} 8+\mathrm{T}$ and $\mathrm{B}$ cells, and suppress the metabolic activity of CD14+ and NK cells. A recent Phase IIb study of 306 patients demonstrated that an oral daily $0.6 \mathrm{mg}$ dose of laquinimod significantly reduced MRI disease activity by a median of $60 \%$ versus placebo in RRMS patients. The majority of the patients that have participated in the trial are now receiving treatment with laquinimod in a continued open-label extension trial. ${ }^{16}$ An ongoing Phase III trial is currently evaluating efficacy of laquinimod (0.6 mg daily) in patients with RRMS. ${ }^{17}$

Laquinimod appears to be well tolerated, with only some transient and dose-dependent increases in liver enzymes. A case of Budd-Chiari syndrome occurred after one month of exposure in a patient with underlying hypercoagulability. Unlike its precursor substance, linomide, no cases of serositis 
or myocardial infarction have been reported so far in patients receiving laquinimod.

\section{BG000I 2 (oral fumarate)}

BG00012 is an oral formulation of dimethyl fumarate. The exact mechanism of action is not known but is thought to inhibit immune cells by stimulating the expression of anti-inflammatory cytokines such as IL-10, IL-4, and IL-5, resulting in a shift from a T helper (Th)-1 (pro-inflammatory) to a Th-2 (anti-inflammatory) T cell response. ${ }^{18}$ In addition, BG00012 may provide a neuroprotective therapeutic effect by inducing phase II detoxification genes, and upregulation of the phase II detoxification enzyme NAD(P)H:quinone oxidoreductase-1 (NQO-1). ${ }^{19}$

A multicenter, randomized, placebo-controlled clinical trial of oral BG00012 involving 257 people with RRMS, receiving various doses of BG00012, demonstrated a dosedependent reduction in active inflammation on MRI scans. ${ }^{20}$ Tolerability was good overall, with adverse events more commonly occurring in the treatment groups, including abdominal pain and flushing. Two Phase III trials are currently ongoing, evaluating whether BG00012 is effective in reducing the proportion of relapses, decreasing the number of brain lesions, and slowing time to progression. ${ }^{21,22}$ Estimated completion dates are in December 2010.

SB-683699 is an oral medication that is thought to inhibit leukocyte trafficking through the BBB by antagonism of alpha 4 integrins. A Phase II trial in patients with RRMS evaluating safety and efficacy of SB-683699 on the development of new brain lesion formation at 6 months as detected by MRI scan as well as accumulation of disability will provide results soon. ${ }^{23}$

\section{Teriflunomide}

Teriflunomide is a dihydroorotate dehydrogenase inhibitor, a mitochondrial enzyme crucially involved in pyrimidine synthesis. Because activated lymphocytes depend on de novo pyrimidine synthesis, pyrimidine depletion results in inhibition of immune-cell proliferation. ${ }^{24}$ There is also some evidence from in vitro studies suggesting that teriflunomide may induce Th-2-mediated anti-inflammatory cytokine activation.

Oral teriflunomide was tested in a randomized, doubleblind, placebo-controlled Phase II study. Patients with relapsing forms of MS were randomized to receive placebo, teriflunomide $7 \mathrm{mg}$, or teriflunomide $14 \mathrm{mg}$ per day for 36 weeks. Teriflunomide demonstrated a dose-dependent reduction on the number of $\mathrm{T}_{1}$-enhancing lesions. Teriflunomide was generally safe and well tolerated. Adverse effects included nasopharyngitis, alopecia, nausea, limb pain, diarrhea, and arthralgia. Hepatic necrosis and pancytopenia have been reported in patients with rheumatoid arthritis who were taking teriflunomide. A 2-year, double-blind, placebocontrolled Phase III study in relapsing MS is in progress. ${ }^{25}$ The primary outcome measure is relapse rate. Other ongoing or planned studies of teriflunomide include a Phase II study of combination with IFN- $\beta$, a Phase II study of combination with glatiramer acetate, and a placebo-controlled Phase III trial in clinically isolated syndrome. ${ }^{26-28}$

\section{Parenteral medications Alemtuzumab}

Alemtuzumab is a humanized monoclonal antibody directed against CD52, a cell surface receptor expressed on lymphocytes, NK cells, monocytes, and macrophages. Binding of the monoclonal antibody to B and $\mathrm{T}$ lymphocytes results in antibody-dependent cell lysis and a prolonged elimination (up to 16 months) of cells from the bone marrow and blood. Interestingly, the capacity of immune cells to regenerate remains intact after repetitive cycles of alemtuzumab, but immature forms of B cells (transitional type I cells), possibly driven by high BAFFs levels, are seen early in the course of immune reconstitution. This event could explain the frequent development of antibody-mediated autoimmune disorders with alemtuzumab therapy. Alemtuzumab is currently US Food and Drug Administration (FDA) approved to treat B-cell chronic lymphocytic leukemia.

Studies of alemtuzumab in the treatment of patients with RRMS and secondary progressive MS (SPMS) have shown efficacy in the suppression of annualized relapse rate but with variable results in preventing progression of disability, depending on stages of the disease. In a recent Phase II randomized blinded clinical trial (IV at $12 \mathrm{mg}$ per day or $24 \mathrm{mg}$ per day for 5 consecutive days during the first month and on 3 consecutive days at 12 and 24 months), alemtuzumab significantly reduced the rate of sustained accumulation of disability by $71 \%$ with a $74 \%$ reduction on the annualized rate of relapse when compared with IFN- $\beta$ - $1 \mathrm{a}$ in patients with early RRMS. Over $80 \%$ of patients receiving alemtuzumab remained relapse free at 36 months. Reduction in $\mathrm{T}_{2}$ lesion volume and total brain volume analysis was greater in the alemtuzumab group. Adverse events in the alemtuzumab group included autoimmunity (thyroid disorders and immune thrombocytopenic purpura) and infections. About one third of patients develop antibodies against the thryrotropin receptor and subsequent autoimmune hyperthyroidism. ${ }^{13}$ 
Currently there are two Phase III trials comparing two annual cycles of intravenous alemtuzumab to three times weekly IFN- $\beta$ - $1 \mathrm{a}$ in treatment naïve patients with RRMS. ${ }^{29,30}$ These studies are expected to be completed in 2011-2012.

Rituximab is a chimeric antibody directed against the human CD20 phosphoprotein that is present on all B cell lineages except for stem cells, pro-B cells, and plasma cells. Rituximab acts by binding to B cell lymphocytes, initiating complement-mediated B cell lysis. The standard dose of rituximab is $375 \mathrm{mg} / \mathrm{m}^{2}$ given weekly for 4 weeks, or a fixed dose of $2 \mathrm{~g}$ divided in two infusions of $1 \mathrm{~g}$ each, 2 weeks apart. Following an intravenous administration of $2 \mathrm{~g}$ rituximab, CD20+ B cells are rapidly depleted and remain undetectable for up to 6 months longer.

Rituximab has shown efficacy in the treatment of patients with RRMS. A recently completed Phase II randomized clinical trial using a biweekly $1000 \mathrm{mg}$ dose of rituximab in RRMS patients demonstrated a 91\% reduction on the number of gadolinium-enhancing lesions on MRI scans, as well as significant reduction in clinical relapses. Mild infusion-related complications were seen in most patients, but serious adverse reactions were rare. ${ }^{14}$ In a recent trial of patients with primary progressive MS, rituximab appeared to have efficacy only in young patients with signs of active inflammation on MRI scans. ${ }^{31}$ Five cases of progressive multifocal leukoencephalopathy have been recently reported in patients receiving rituximab for the treatment of rheumatoid arthritis and systemic lupus erythematosus. However, those patients were receiving additional immunosuppressants. Ocrelizumab, a humanized monoclonal antibody against human CD20, is currently under investigation in a Phase II trial evaluating efficacy and safety in patients with RRMS. Estimated completion of the trial is $2012 .{ }^{32}$

Daclizumab is a humanized mouse monoclonal antibody that binds to the alpha subunit of the IL-2 receptor. This receptor is present on activated $\mathrm{T}$ and $\mathrm{B}$ cells and is crucial for $\mathrm{T}$ cell proliferation and activation. The clinical benefit of daclizumab has been linked to significant expansion of immunoregulatory CD56 NK cells, and subsequent downregulation of adaptive $\mathrm{T}$ cell responses (CD4+ and CD8+ T cells). ${ }^{33}$ In a first open-label study with intravenous daclizumab (1 mg/kg dose), five patients with SPMS and six patients with RRMS demonstrated a decrease of contrast-enhancing lesions by $78 \%$ and in a relapse rate by $81 \%$ compared with baseline. ${ }^{34} \mathrm{~A}$ recent open-label Phase II trial using subcutaneous daclizumab $(2 \mathrm{mg} / \mathrm{kg}$ doses) in MS patients with inadequate response to IFN therapy demonstrated a $72 \%$ reduction in the number of new or enlarged contrast-enhancing MRI lesions at week 24 compared with patients receiving IFN- $\beta$ alone. Because type 1 IFNs are known to also enhance NK-cell function, the question of possible synergism between IFN and daclizumab therapy is possible. ${ }^{35}$ Skin rash, chest discomfort, headaches, lymphopenia, generalized lymphadenopathy, and transient elevation of liver function tests and bilirubin level were reported. Daclizumab is already in clinical use to prevent rejection of kidney transplants. A multicenter Phase II trial investigating a subcutaneous formulation of daclizumab (DacHyp) monotherapy is ongoing.

CTLA4Ig is a chimeric fusion protein that prevents $\mathrm{T}$ cell activation by binding the B7-1 and B7-2 costimulatory molecules on antigen-presenting cells.

Table I Summary of characteristics, efficacy, and safety information on selected MS therapies

\begin{tabular}{|c|c|c|c|c|}
\hline & Mechanism of action & Route/dose & Results & AEDs \\
\hline Alemtuzumab & Anti-CD52 & IV I 2 mg dose/y & $\begin{array}{l}75 \% \downarrow \text { SAD (12 mg dose), } \\
74 \% \downarrow \text { RR }\end{array}$ & ITP (3 pts), Graves (20\%) \\
\hline Daclizumab & $\begin{array}{l}\text { Anti-CD25/anti-IL2, } \\
\text { NK CD56 }\end{array}$ & SQ 2 mg/kg (Q2w) & $\begin{array}{l}72 \% \downarrow \text { CEL in RRMS } \\
\text { patients }\end{array}$ & $\begin{array}{l}\text { Skin rash, chest discomfort, } \\
\text { headaches, lymphopenia }\end{array}$ \\
\hline Rituximab & Anti-CD20 & IV (I g dose,Q2w, ×2) & $91 \% \downarrow C E L$ in RRMS & Infusion reaction, allergies \\
\hline Fingolimod & $\begin{array}{l}\text { Sphingosine-I-phosphate } \\
\text { (SIP) analog }\end{array}$ & Oral (0.5 and I.25 mg) & $54 \%-60 \% \downarrow$ ARR & $\begin{array}{l}\text { Bradycardia, nasopharyngitis, dyspnea, } \\
\text { headaches, diarrhea and nausea, } \\
\text { hemorrhagic encephalitis, skin cancer }\end{array}$ \\
\hline Laquinimod & Anti-inflammatory & Oral $0.6 \mathrm{mg} / \mathrm{d}$ & $40 \% \downarrow C E L$ & LFT elevation, Budd-Chiari \\
\hline Fumaric acid (BGI2) & $\begin{array}{l}\text { Anti-inflammatory/ } \\
\text { neuroprotective }\end{array}$ & Oral (I 20-240 mg TID) & $69 \% \downarrow C E L$ & $\begin{array}{l}\text { Diarrhea, cramps, nausea } \\
\text { and flushing }\end{array}$ \\
\hline Teriflunomide & $\begin{array}{l}\text { Inhibition of immune } \\
\text { cell proliferation }\end{array}$ & Oral (7 and I4 mg dose) & $61 \% \downarrow C E L$ & $\begin{array}{l}\text { Nasopharyngitis, alopecia, nausea, limb } \\
\text { pain, diarrhea, and arthralgia }\end{array}$ \\
\hline Cladribine & $\begin{array}{l}\text { Purine nucleoside } \\
\text { analog }\end{array}$ & $\begin{array}{l}\text { Oral ( } 3.5 \text { and } 5.25 \mathrm{mg} / \mathrm{kg} \\
\text { total dose) }\end{array}$ & $\begin{array}{l}58 \% \downarrow R R, \\
43 \% \text { disease free }\end{array}$ & $\begin{array}{l}\text { HZV, lymphopenia, HA, } \\
\text { nasopharyngitis, lymphopenia }\end{array}$ \\
\hline
\end{tabular}

Abbreviations: ARR, annualized relapse rate; CEL, contrast enhancing MRI lesions; HA, headaches; HZV, herpes zoster virus; ITP, immune thrombocytopenic purpura; IV, intravenous; LFT, liver function test; RR, relapse rate; RRMS, relapsing remitting multiple sclerosis; SAD, sustained acumulation of disability; SQ, subcutaneous. 
A recent Phase I clinical trial showed that intravenous administration of CTLA4Ig was well tolerated in patients with MS, and most adverse events were rated as mild. Lymphadenopathy, urinary tract infections, headaches, blurred vision, and upper respiratory tract infections were most frequently reported. Immunologic assessment of the patients showed a reduction in myelin basic protein (MBP) proliferation within 2 months of infusion and decreased IFN- $\gamma$ production by MBP-specific lines. No significant changes in clinical or MRI parameters were observed during the duration of the study. ${ }^{36}$

\section{Comments}

The etiology of MS remains unclear; however, there has been a significant progress in our knowledge of the basic pathophysiological mechanisms involved in the disease process. Clinicopathological studies suggest a high level of heterogeneity among MS patients. In addition, recent studies suggest that endogenous expression of certain cytokines might impact on the clinical efficacy of currently available therapies. ${ }^{37}$ Considering the complex mechanisms of action of current and emerging therapies, it is imperative to promote the development of biomarkers that might have predictive value in identifying future response to various therapies.

\section{Disclosure}

The authors report no conflicts of interest in this work.

\section{References}

1. Seto S, Carrera CJ, Kubota M, Wasson DB, Carson DA. Mechanism of deoxyadenosine and 2-chlorodeoxyadenosine toxicity to nondividing human lymphocytes. J Clin Invest. 1985;75(2):377-383.

2. Lassmann H, Lucchinetti CF. Cortical demyelination in CNS inflammatory demyelinating diseases. Neurology. 2008;70(5):332-333.

3. Davies GR, Ramio-Torrenta L, Hadjiprocopis A, et al. Evidence for grey matter MTR abnormality in minimally disabled patients with early relapsing-remitting multiple sclerosis. J Neurol Neurosurg Psychiatry. 2004;75(7):998-1002.

4. Spurgeon S, Yu M, Phillips JD, Epner EM. Cladribine: not just another purine analogue? Expert Opin Investig Drugs. 2009;18(8):1169-1181.

5. Serono E; ClinicalTrials.gov. CLARITY A phase III, randomized, double-blind, three-arm, placebo-controlled, multi-center study to evaluated the safety and efficacy of oral cladribine in subjects with relapsing-remitting multiple sclerosis. 2009. Available from: http:// clinicaltrials.gov/ct2/show/nct00213135. Accessed 2010 Aug 20.

6. Havrdova E, Galetta S, Hutchinson M, et al. Effect of natalizumab on clinical and radiological disease activity in multiple sclerosis: a retrospective analysis of the Natalizumab Safety and Efficacy in Relapsing-Remitting Multiple Sclerosis (AFFIRM) study. Lancet Neurol. 2009;8(3):254-260.

7. Giovannoni Gea. Safety and tolerability of cladribine tablets in relapsingremitting multiple sclerosis during the 96-week, phase III, double-blind, placebo-controlled CLARITY study. Presentation at ECTRIMS 2009, Dusseldorf, Germany. 2009.
8. Mehling M, Brinkmann V, Antel J, et al. FTY720 therapy exerts differential effects on T cell subsets in multiple sclerosis. Neurology. 2008;71(16):1261-1267.

9. Brinkmann V. FTY720 (fingolimod) in multiple sclerosis: therapeutic effects in the immune and the central nervous system. Br J Pharmacol. 2009;158(5):1173-1182.

10. Brinkmann V, Wilt C, Kristofic C, et al. FTY720: dissection of membrane receptor-operated, stereospecific effects on cell migration from receptor-independent antiproliferative and apoptotic effects. Transplant Proc. 2001;33(7-8):3078-3080.

11. Pinschewer DD, Ochsenbein AF, Odermatt B, Brinkmann V, Hengartner H, Zinkernagel RM. FTY720 immunosuppression impairs effector $\mathrm{T}$ cell peripheral homing without affecting induction, expansion, and memory. J Immunol. 2000;164(11):5761-5770.

12. Miron VE, Ludwin SK, Darlington PJ, et al. Fingolimod (FTY720) enhances remyelination following demyelination of organotypic cerebellar slices. Am J Pathol. 2010;176(6):2682-2694.

13. Coles AJ, Compston DA, Selmaj KW, et al. Alemtuzumab vs interferon beta-1a in early multiple sclerosis. N Engl J Med. 2008;359(17): 1786-1801.

14. Hauser SL, Waubant E, Arnold DL, et al. B-cell depletion with rituximab in relapsing-remitting multiple sclerosis. $N$ Engl J Med. 2008; 358(7):676-688.

15. Yang JS, Xu LY, Xiao BG, Hedlund G, Link H. Laquinimod (ABR215062) suppresses the development of experimental autoimmune encephalomyelitis, modulates the Th1/Th2 balance and induces the Th3 cytokine TGF-beta in Lewis rats. J Neuroimmunol. 2004; 156(1-2):3-9.

16. Comi G, Pulizzi A, Rovaris M, et al. Effect of laquinimod on MRImonitored disease activity in patients with relapsing-remitting multiple sclerosis: a multicentre, randomised, double-blind, placebo-controlled phase IIb study. Lancet. 2008;371(9630):2085-2092.

17. Teva Pharmaceutical Industries. A multinational, multicenter, openlabel, single-assignment extension of the MS-LAQ-301 Study, to evaluate the long-term safety, tolerability and effect on disease course of daily oral laquinimod $0.6 \mathrm{mg}$ in subjects with relapsing multiple sclerosis. NCT00988052.

18. de Jong R, Bezemer AC, Zomerdijk TP, van de Pouw-Kraan T, Ottenhoff TH, Nibbering PH. Selective stimulation of T helper 2 cytokine responses by the anti-psoriasis agent monomethylfumarate. Eur J Immunol. 1996;26(9):2067-2074.

19. Wierinckx A, Breve J, Mercier D, Schultzberg M, Drukarch B, van dam AM. Detoxication enzyme inducers modify cytokine production in rat mixed glial cells. J Neuroimmunol. 2005;166(1-2):132-143.

20. Schimrigk S, Brune N, Hellwig K, et al. Oral fumaric acid esters for the treatment of active multiple sclerosis: an open-label, baseline-controlled pilot study. Eur J Neurol. 2006;13(6):604-610.

21. BiogenIdec; ClinicalTrials.gov. A randomized, multicenter, placebocontrolled and active reference (glatiramer acetate) comparison study to evaluate the efficacy and safety of BG00012 in subjects with relapsingremitting multiple sclerosis (CONFIRM). 2010. Available from: http:// clinicaltrials.gov/ct2/show/nct00451451. Accessed 2010 Aug 20.

22. BiogenIdec; ClinicalTrials.gov. A randomized, multicenter, doubleblind, placebo-controlled, dose-camparison study to determine the efficacy and safety of BG00012 in subjects with relaping-remitting multiple sclerosis (DEFINE). 2010. Available from: http://clinicaltrials. gov/ct2/show/nct00420212. Accessed 2010 Aug 20.

23. GlaxoSmithKline; ClinicalTrials.gov. Randomised, double-blind, placebo-controlled, parallel-group, dose-ranging study to investigate the MRI efficacy and the safety of six months administration of SB-683699 in subjects with relapsing-remitting multiple sclerosis (MS). 2008. Available from: http://clinicaltrials.gov/ct2/show/nct00395317. Accessed 2010 Aug 20.

24. Korn T, Magnus T, Toyka K, Jung S. Modulation of effector cell functions in experimental autoimmune encephalomyelitis by leflunomide - mechanisms independent of pyrimidine depletion. J Leukoc Biol. 2004;76(5):950-960. 
25. Sanofi-Aventis; ClinicalTrials.gov. Long-term extension of the multinational, double-blind, placebo controlled study EFC6049 (HMR1726D/3001) to document the safety of two doses of teriflunomide ( 7 and $14 \mathrm{mg}$ ) in patients with multiple sclerosis with relapses; 2010. Available from: http://clinicaltrials.gov/ct2/show/nct00803049. Accessed 2010 Aug 20.

26. Sanofi-Aventis; ClinicalTrials.gov. A randomized, multinational, double-blind, placebo-controlled, parallel-group design pilot study to estimate the tolerability, safety, pharmacokinetics, and pharmacodynamic effects of teriflunomide for 24 weeks when added to treatment with glatiramer acetate in subjects with multiple sclerosis. 2009. Available from: http://clinicaltrials.gov/ct2/show/nct00475865. Accessed 2010 Aug 20.

27. Sanofi-Aventis; ClinicalTrials.gov. A randomized, multinational, double-blind, placebo-controlled, parallel-group design pilot study to estimate the tolerability, safety, pharmacokinetics, and pharmacodynamic effects of teriflunomide for 24 weeks when added to treatment with interferon-beta in subjects with multiple sclerosis. 2010. Available from: http://clinicaltrials.gov/ct2/show/nct00489489. Accessed 2010 Aug 20.

28. Sanofi-Aventis; ClinicalTrials.gov. An international, multi-center, randomized, double-blind, placebo-controlled, parallel group study to evaluate the efficacy and safety of two year treatment with teriflunomide $7 \mathrm{mg}$ once daily and $14 \mathrm{mg}$ once daily versus placebo in patients with a first clinical episode suggestive of multiple sclerosis. 2010. Available from: http://clinicaltrials.gov/ct2/show/nct00622700. Accessed 2010 Aug 20.

29. Genzyme/Bayer; ClinicalTrials.gov. Comparison of Alemtuzumab and Rebif ${ }^{\circledR}$ Efficacy in Multiple Sclerosis, Study One (CARE-MS I). 2010. Available from: http://clinicaltrials.gov/ct2/show/nct00530348. Accessed 2010 Aug 20.
30. Genzyme/Bayer; ClinicalTrials.gov. Comparison of Alemtuzumab and Rebif ${ }^{\circledR}$ Efficacy in Multiple Sclerosis, Study Two (CARE-MS II) 2010. Available from: http://clinicaltrials.gov/ct2/show/nct00548405. Accessed 2010 Aug 20.

31. Hawker K, O'Connor P, Freedman MS, et al. Rituximab in patients with primary progressive multiple sclerosis: results of a randomized double-blind placebo-controlled multicenter trial. Ann Neurol. 2009; 66(4):460-471.

32. Genentech H-LR; ClinicalTrials.gov. A study of the efficacy and safety of ocrelizumab in patients with relapsing-remitting multiple sclerosis. 2010. Available from: http://clinicaltrials.gov/ct2/show/nct00676715. Accessed 2010 Aug 20.

33. Bielekova B, Catalfamo M, Reichert-Scrivner S, et al. Regulatory CD56(bright) natural killer cells mediate immunomodulatory effects of IL-2Ralpha-targeted therapy (daclizumab) in multiple sclerosis. Proc Natl Acad Sci U S A. 2006;103(15):5941-5946.

34. Bielekova B, Richert N, Howard T, et al. Humanized anti-CD25 (daclizumab) inhibits disease activity in multiple sclerosis patients failing to respond to interferon beta. Proc Natl Acad Sci U S A. 2004; 101(23):8705-8708.

35. Bielekova B, Howard T, Packer AN, et al. Effect of anti-CD25 antibody daclizumab in the inhibition of inflammation and stabilization of disease progression in multiple sclerosis. Arch Neurol. 2009;66(4):483-489.

36. Viglietta V, Bourcier K, Buckle GJ, et al. CTLA4Ig treatment in patients with multiple sclerosis: an open-label, phase 1 clinical trial. Neurology. 2008;71(12):917-924.

37. Axtell RC, de Jong BA, Boniface $\mathrm{K}$, et al. T helper type 1 and 17 cells determine efficacy of interferon-beta in multiple sclerosis and experimental encephalomyelitis. Nat Med. 2010;16(4):406-412.
Journal of Experimental Pharmacology

\section{Publish your work in this journal}

The Journal of Experimental Pharmacology is an international, peerreviewed, open access journal publishing original research, reports, reviews and commentaries on all areas of laboratory and experimental pharmacology. The manuscript management system is completely online and includes a very quick and fair peer-review system.

\section{Dovepress}

Visit http://www.dovepress.com/testimonials.php to read real quotes from published authors. 